\title{
Estrogen receptor beta expression correlates with proliferation in desmoid tumors
}

\section{Santti, Kirsi}

2019-06

Santti , K, Ihalainen , H , Rönty , M , Karlsson , C , Haglund, C , Sampo , M , Tarkkanen , M \& Blomqvist, C 2019 , ' Estrogen receptor beta expression correlates with proliferation in desmoid tumors ' , Journal of Surgical Oncology , vol. 119 , no. 7 , pp. 873-879 . https://doi.org/10.1002/jso.25407

http://hdl.handle.net/10138/312947

https://doi.org/10.1002/jso.25407

draft

Downloaded from Helda, University of Helsinki institutional repository.

This is an electronic reprint of the original article.

This reprint may differ from the original in pagination and typographic detail.

Please cite the original version. 


\title{
Estrogen receptor beta expression correlates with proliferation in desmoid tumors
}

\author{
Kirsi Santti MD ${ }^{1}$ (1) Hanna Ihalainen MD ${ }^{1,2}$ | Mikko Rönty MD, PhD \\ Christina Karlsson MSc ${ }^{4}$ | Caj Haglund MD, $\mathrm{PhD}^{5,6}$ | Mika Sampo MD, PhD ${ }^{3}$ | \\ Maija Tarkkanen MD, $\mathrm{PhD}^{1}$ | Carl Blomqvist MD, $\mathrm{PhD}^{1,7}$
}

\author{
${ }^{1}$ Department of Oncology, Comprehensive \\ Cancer Center, Helsinki University Hospital \\ and University of Helsinki, Helsinki, Finland \\ ${ }^{2}$ Department of Plastic Surgery, Helsinki \\ University Hospital and University of Helsinki, \\ Helsinki, Finland \\ ${ }^{3}$ Department of Pathology, HUSLAB and \\ University of Helsinki, Helsinki, Finland \\ ${ }^{4}$ Department of Medical Diagnostics, School \\ of Health Sciences, Örebro University, Örebro, \\ Sweden \\ ${ }^{5}$ Department of Surgery, Helsinki University \\ Hospital and University of Helsinki, Helsinki, \\ Finland \\ ${ }^{6}$ Translational Cancer Biology, Reseach \\ Programs Unit, University of Helsinki, \\ Helsinki, Finland \\ ${ }^{7}$ Department of Oncology, Örebro University \\ Hospital, Örebro, Sweden

\section{Correspondence} \\ Kirsi Santti, Comprehensive Cancer Center, \\ Helsinki University Hospital, PO Box 180, \\ 00029 HUS, Helsinki, Finland. \\ Email: kirsi.santti@hus.fi \\ Funding information \\ Sigrid Juséliuksen Säätiö; Finska \\ Läkaresällskapet; Medicinska \\ Understödsföreningen Liv och Hälsa; Helsinki \\ University Hospital Research funds
}

\begin{abstract}
Background and objectives: Estrogen receptor signaling and cyclin D1 have a major role in tumor cell proliferation in breast cancer. Desmoid tumors are rare neoplasms that may respond to endocrine treatment. The present study aimed to investigate the expression levels and the clinical relevance of estrogen receptor beta (ER $\beta$ ) and cyclin D1 in desmoid tumors.
\end{abstract}

Methods: This study consists of 83 patients with a surgically treated desmoid tumor. ER $\beta$ and cyclin D1 expression was examined by immunohistochemistry in tissue microarrays. Cyclin A and Ki67 were studied in our previous work.

Results: Median ER $\beta$ expression was 10.8\%. ER $\beta$ expression correlated with expression of the proliferation antigens $\mathrm{Ki67}\left(r_{\mathrm{p}}=0.35, P=0.003\right)$, cyclin D1 $\left(r_{p}=0.34, P=0.004\right)$, and cyclin $A\left(r_{p}=0.34, P=0.004\right) . E R \beta$ immunoexpression showed a trend towards predictive impact for recurrence as a continuous variable. Further explorative analysis indicated that very high ER $\beta$ expression was related to high risk of relapse (hazard ratio $[\mathrm{HR}] 2.6 ; P=0.02$ ).

Median cyclin D1 expression was 15.6\%. High cyclin D1 expression was associated with high Ki67 and cyclin A expression. Cyclin D1 was not associated with time to recurrence.

Conclusions: ER $\beta$ and cyclin D1 immunopositivity correlated with high proliferation in desmoid tumors. High ER $\beta$ expression might be predictive for postoperative recurrence.

\section{KEYWORDS}

aggressive fibromatosis, biomarkers, cyclins, immunohistochemistry, steroid receptors

\section{1 | INTRODUCTION}

Desmoid tumors (desmoid fibromatosis) are locally aggressive tumors with elevated incidence during pregnancy and at postpartum suggesting a hormonal influence. ${ }^{1}$ Pregnancy-associated tumors typically arise in the abdominal wall while other desmoids can occur in different parts of the body in musculoaponeurotic tissues. Tumors show pathognomonic mutation either in the APC gene or in the $\beta$-catenin gene CTNNB1, which causes a disruption in the canonical $\mathrm{Wnt} / \beta$-catenin pathway. Active surveillance is an alternative for indolent desmoid tumors without critical location. When therapy is indicated, surgery, radiotherapy, and systemic therapy including endocrine therapy are utilized.

The function of the nuclear receptor family member estrogen receptor beta $(E R \beta)$ varies in different tissues, cancer types, and stages. The role of ER signaling has long remained elusive in desmoid 
tumors. Early reports on desmoid tumors showed no estrogen receptor expression. The discovery of the second main estrogen receptor isoform, $E R \beta$, subsequently led to positive $E R \beta$ findings in desmoid tumors. ${ }^{2}$ The vast majority of desmoid tumors express ER $\beta$ but not estrogen receptor alpha $(E R \alpha) .^{3}$ Selective estrogen receptor modulators such as tamoxifen act on both receptor subtypes. ${ }^{4}$ However, in contrast to breast cancer, estrogen receptor expression was not predictive for response to endocrine therapy in desmoid tumors in a small retrospective study. ${ }^{5}$

Cyclin D1 is a cell cycle promoter frequently overexpressed in neoplastic cells. Accumulated $\beta$-catenin may induce cyclin D1 transcription as a coregulator in desmoid tumors. ${ }^{6}$ Cyclin D1 activates cyclin-dependent kinases (Cdk) 4 and 6, which function as a complex in transition from $G 1$ checkpoint to the $S$ phase by phosphorylating the retinoblastoma tumor suppressor protein. ERa upregulates cyclin D1 in breast cancer and thus inhibition of ER $\alpha$ with endocrine agents results in cell cycle arrest. ${ }^{7}$ In hormone refractory breast cancer and other cancers, various proliferative pathways may induce cyclin D1 and Cdk 4/6, such as PI3K. ${ }^{8}$ Highly specific Cdk inhibitors target Cdk 4 and 6 and act synergistically with hormonal therapy in breast cancer. ${ }^{9,10}$ An overall survival benefit was reported in a randomized trial with the first-in-class Cdk 4/6 inhibitor palbociclib combined with fulvestrant in locoregionally advanced or metastatic hormone receptor-positive HER2-negative breast cancer. ${ }^{11}$ Overall survival results from trials with the $\mathrm{Cdk}$ 4/6 inhibitors ribociclib and abemaciclib are pending, but both prolong time to progression similarly to palbociclib. ${ }^{12,13}$

Little information is available about the expression and tumor biological roles of ER $\beta$ and cyclin D1 in desmoid tumors. Our study aimed to investigate the immunohistochemical expression of cyclin $\mathrm{D} 1$ and ER $\beta$ and their association with clinicopathological features and prediction of recurrence in desmoid tumors.

\section{2 | MATERIALS AND METHODS}

\section{1 | Patients}

Desmoid tumor patients treated at Helsinki University Hospital between 1987 and 2011 were included. A sarcoma expert pathologist (MR) reviewed the histopathologic diagnosis and confirmed it for all the included 90 patients. Clinical data were collected from the patient records. The Ethics Committee of Helsinki University Hospital (270/13/03/00/2011) and the Ministry of Welfare and Health approved this retrospective study. The study followed the Declaration of Helsinki.

\section{2 | Tissue arrays and immunohistochemistry}

The tissue microarray (TMA) and immunohistochemical procedures are described in our previous work. ${ }^{14}$ Briefly, the TMA was constructed of formalin-fixed paraffin-embedded desmoid tumor tissue specimen. The TMA blocks were cut into 4- $\mu$ m slices. After antigen retrieval in Tris-EDTA buffer $(\mathrm{pH}$ 9), the immunostaining were generated with mouse monoclonal cyclin D1 antibody (Ventana Medical Systems, Tucson, AZ; prediluted in Ventana diluent) and ER $\beta$ antibody (Ventana Medical Systems, Tucson, AZ; dilution 1:100).

The TMA sections were digitalized with Pannoramic 250 scanner (2DHistech, Budapest, Hungary). Representative areas were annotated and evaluated in Pannoramic Viewer and NuclearQuant (3DHistech, Budapest, Hungary) software modules, respectively. Immunostaining was scored as continuous percentages of positive nuclear staining. A minimum of 100 cells for ER $\beta$ and 300 cells for cyclin D1 were regarded as evaluable. If over 500 cells were detected in a cyclin D1 specimen, this score was chosen. If multiple scores with over 500 cells were recognized for one patient, the highest score was accepted. Expression of ER $\beta$ and cyclin D1 was scored with an image analysis software, as previously prescribed for the proliferation antigens $\mathrm{Ki} 67$ and cyclin A. ${ }^{14}$ Cut-offs for positive expression was set at $1 \%$ for $\operatorname{ER} \beta$ and both at $5 \%$ and at $10 \%$ for cyclin D1 (Figure 1). $\mathrm{Ki} 67$ and cyclin A expression were examined in our previous study. ${ }^{14}$

\section{3 | Statistical analysis}

Statistical analysis was performed with SPSS 25 software (SPSS, Chicago, IL). Pearson's correlation coefficient was used with continuous variables and the student $t$ test for dichotomous variables for testing the association of ER $\beta$ and cyclin D1 and other variables. Two alternative cut-offs for ER $\beta$ was used in these models, $1 \%$ and $28.7 \%$ (at 70th percentile). The association between cyclin D1 expression and proliferation was tested separately in ER $\beta$-positive and -negative groups in a mixed general ANOVA model (Table S1). $P$ value was considered significant when $<0.05$. All $P$ values were twotailed. Cox regression model and Kaplan-Meier estimates were used to analyze the association between cyclin D1 or ER $\beta$ expression and time to recurrence (TTR). Since there was an association between cyclin D1 and use of postoperative radiotherapy, TTR analyses were stratified for radiotherapy. In addition to analyses with cyclin D1 or $E R \beta$ as continuous values, exploratory TTR analyses with cut-offs ranging from the $10 \%$ to the $90 \%$ deciles were also performed. Kaplan-Meier plots of TTR with cyclin D1 and ER $\beta$ divided into tertiles were generated to detect any nonlinear association.

\section{3 | RESULTS}

Cyclin D1 and ER $\beta$ expression were evaluable in 77 and 83 of 90 patients, respectively. Due to missing and unsuccessful immunostaining or too low a cell number, 13 and 7 patients were excluded from the analyses. The median follow-up period was 11 years (range from 0.1 to 29 years). Clinical features and associations with cyclin D1 and ER $\beta$ expression are listed in Table 1.

\section{1 | Expression of cyclin D1 and ER $\beta$}

Cyclin D1 expression varied from 0.7 to $90.7 \%$ (mean $20.1 \%$, median $15.6 \%$, and interquartile range $21.0 \%$ ). The 
FIGURE 1 Immunohistochemical expression of cyclin D1 and estrogen receptor beta $(E R \beta)$ in desmoid tumors: (A) low $E R \beta<1 \%$, (B) high $E R \beta \geq 1 \%$, (C) low cyclin D1 $<5 \%$, and (D) high cyclin D1 $\geq 5 \%$ [Color figure can be viewed at wileyonlinelibrary.com]
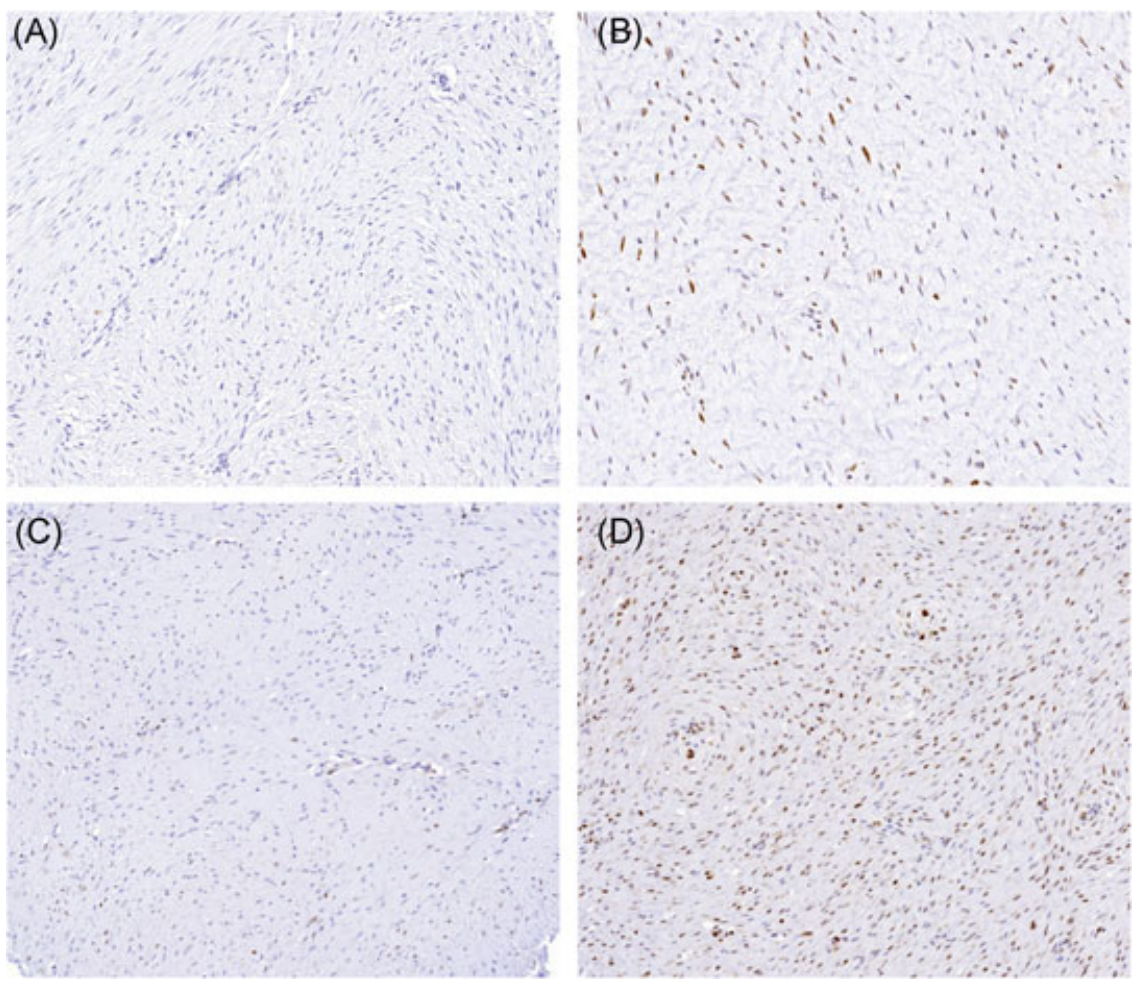

distribution was highly skewed with predominantly low values (Figure S1). With a 5\% cut-off, cyclin D1 was expressed in 63 of 77 patients (82\%) and with a 10\% cut-off in 64\%. Nuclear ER $\beta$ expression varied from $0 \%$ to $74 \%$ (mean $19.3 \%$, median $10.8 \%$, and interquartile range $31.1 \%$ ). Like for cyclin D1, the distribution was skewed towards low expression values (Figure S2). With a $1 \%$ cut-off, ER $\beta$ was positive in 68 of 83 patients (82\%).

\section{2 | Associations between clinical variables, proliferation, and immunohistochemical expression of cyclin D1 and ERß}

Cyclin D1 expression correlated positively with ER $\beta\left(r_{\mathrm{p}}=0.34\right.$, $P=0.004)$, Ki67 $\left(r_{p}=0.40, P=0.001\right)$, and cyclin A $\left(r_{p}=0.34\right.$, $P=0.004)$. Cyclin D1 expression was significantly higher in males $(P=0.047)$, and on patients receiving postoperative radiotherapy $(P=0.006$; Tables 1 and 2$)$. In addition to cyclin D1, ER $\beta$ expression correlated with $\mathrm{Ki67}\left(r_{\mathrm{p}}=0.35, \mathrm{P}=0.003\right)$ and cyclin $\mathrm{A}\left(r_{\mathrm{p}}=0.40, P<0.001\right)$. Neither cyclin D1 nor ER $\beta$ expression was associated with tumor size or location, patient age, sex, surgical margin, pregnancy or familial adenomatous polyposis (FAP). ER $\beta$ expression was not associated with sex or postoperative radiotherapy.

Separate analyses of the association between cyclin D1 and proliferation were done in ER $\beta$-negative and -positive groups to detect any modifying effect of ER expression of this association. The correlation between cyclin D1 expression and proliferation was similar in both ER $\beta$-negative and -positive groups with no sign of statistically significant interaction (Table S1).

\section{3 | Prediction of recurrence}

Cyclin D1 overexpression was not significantly associated with TTR neither as a continuous variable nor when divided into two groups by different cut-offs and stratified by postoperative radiotherapy (Table 3; Figure S3). As a continuous variable, ER $\beta$ expression showed a trend towards an increased risk of recurrence (hazard ratio [HR] 1.02, 95\% Cl=1.0-1.04; $P=0.06$ ). Dividing the patient material into two groups with varying cut-offs, on the other hand, revealed a significant association between high ER $\beta$ expression and higher risk of recurrence at the 70 th and 80 th deciles (cut-offs $28.9 \%$ and $38.4 \%$, and $P$ values 0.02 and 0.04 , respectively, Table 3). Figure 2 illustrates the Kaplan-Meier curves of ER $\beta$ expression and TTR at the optimal cut-off of $28.9 \%$.

\section{4 | DISCUSSION}

In the present study, we demonstrate that ER $\beta$ expression correlates with high cyclin D1, Ki67, and cyclin A expression in desmoid tumors. To the best of our knowledge, the association between proliferation and ER $\beta$ expression has not been described before in desmoid tumors. ER $\beta$ or cyclin D1 exhibited no predictive impact on recurrence after surgery in the main analysis. However, explorative analysis using different cut-off values demonstrated a significant negative association between very high expression of ER $\beta$ and TTR. Due to their exploratory nature, the significant association between high ER $\beta$ and a short TTR has to be confirmed in an independent patient cohort. The biological rationale for an association between high ER $\beta$ and high risk of recurrence may be the positive correlation between ER $\beta$ and proliferation found in the present study. Our 


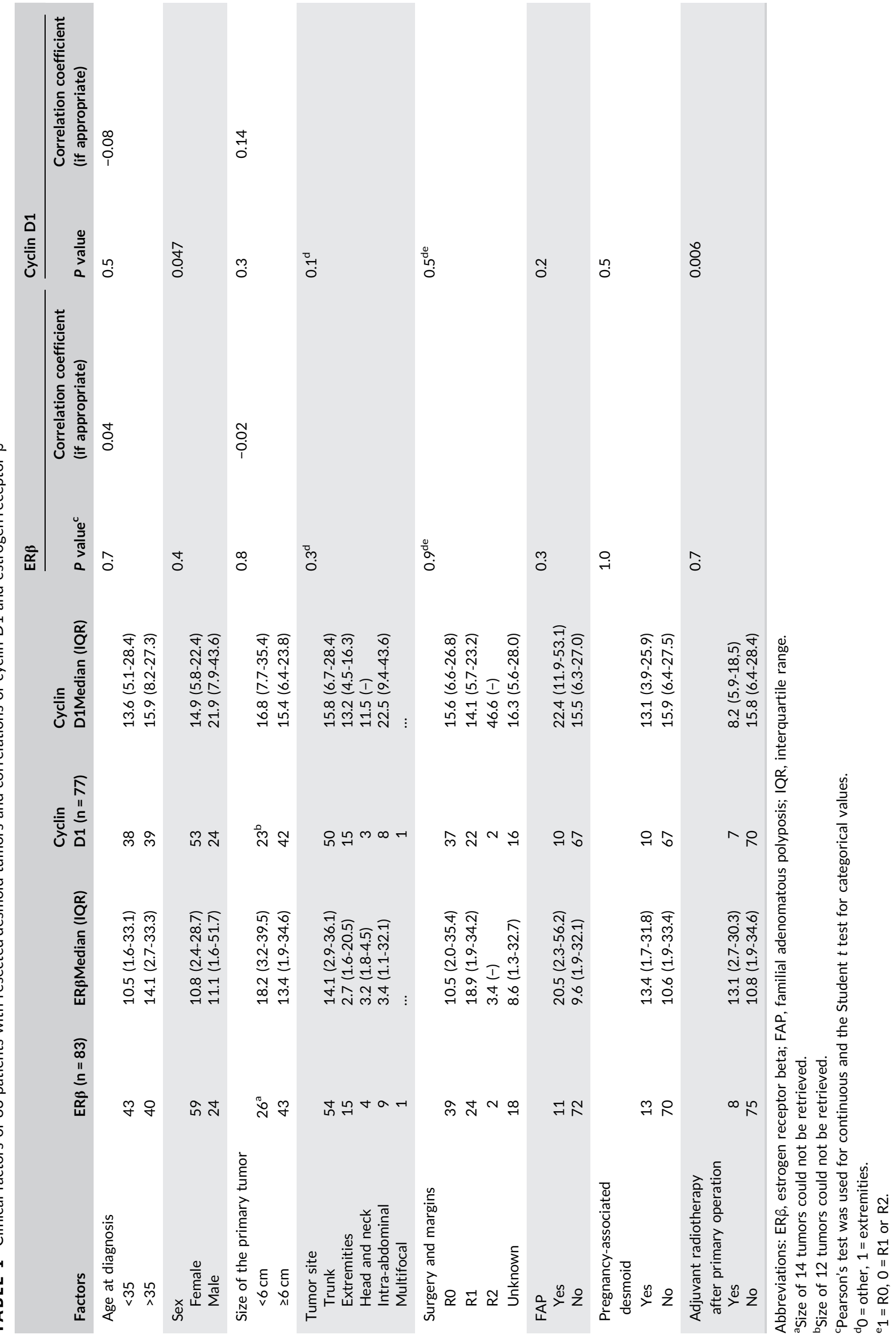


TABLE 2 Correlations of estrogen receptor $\beta(E R \beta)$ and cyclin D1

\begin{tabular}{|c|c|c|c|c|c|}
\hline Factors & Median \% (IQR) & \multicolumn{2}{|c|}{ Cyclin D1 } & \multicolumn{2}{|l|}{ ER $\beta$} \\
\hline ER $\beta$ & $10.8(31.1)$ & 0.004 & 0.34 & & \\
\hline Ki67 & & 0.001 & 0.40 & 0.003 & 0.35 \\
\hline Cyclin A & & 0.004 & 0.34 & 0.001 & 0.40 \\
\hline
\end{tabular}

Abbreviations: $E R \beta$, estrogen receptor beta; IQR, interquartile range.

TABLE 3 Cyclin D1 and ER $\beta$ expression classified from 10th to 90th percentiles in Cox univariate analysis

\begin{tabular}{|c|c|c|c|c|c|c|}
\hline \multirow[b]{2}{*}{ Cut-off \% } & \multicolumn{3}{|l|}{ Cyclin D1 $^{\mathrm{a}}$} & \multicolumn{3}{|l|}{ ER $\beta$} \\
\hline & Cut-off \% & HR (95\% Cl) & $P$ value & Cut-off \% & HR (95\% CI) & $P$ value \\
\hline 10 & 2.9 & $0.8(0.2-3.6)$ & 0.8 & 0.4 & $2.9(0.4-21.3)$ & 0.3 \\
\hline 30 & 7.8 & $1.9(0.6-5.9)$ & 0.2 & 2.4 & $1.3(0.5-3.3)$ & 0.6 \\
\hline 40 & 11.5 & $1.9(0.7-5.0)$ & 0.2 & 4.5 & $1.7(0.7-4.0)$ & 0.3 \\
\hline 60 & 18.5 & $0.7(0.2-1.7)$ & 0.4 & 17.8 & $1.8(0.8-4.0)$ & 0.2 \\
\hline 70 & 22.8 & $0.6(0.2-1.7)$ & 0.3 & 28.7 & $2.6(1.2-6.0)$ & 0.02 \\
\hline 80 & 29.6 & $0.5(0.1-1.9)$ & 0.3 & 38.4 & $2.5(1.1-5.9)$ & 0.04 \\
\hline 90 & 46.5 & $1.1(0.3-5.1)$ & 0.8 & 54.8 & $2.1(0.7-6.3)$ & 0.2 \\
\hline
\end{tabular}

Abbreviations: $\mathrm{Cl}$, confidence interval; $\mathrm{ER} \beta$, estrogen receptor beta; HR, hazard ratio.

${ }^{\mathrm{a} C y c l i n} \mathrm{D} 1$ analysis was stratified by postoperative radiotherapy.

previous observation was that high proliferation is associated with a higher recurrence risk. $^{14}$ We found no indication of a linear association between cyclin D1 expression and TTR, although cyclin D1 expression was also associated with higher proliferation rate measured by the expression of Ki67 and cyclin A.

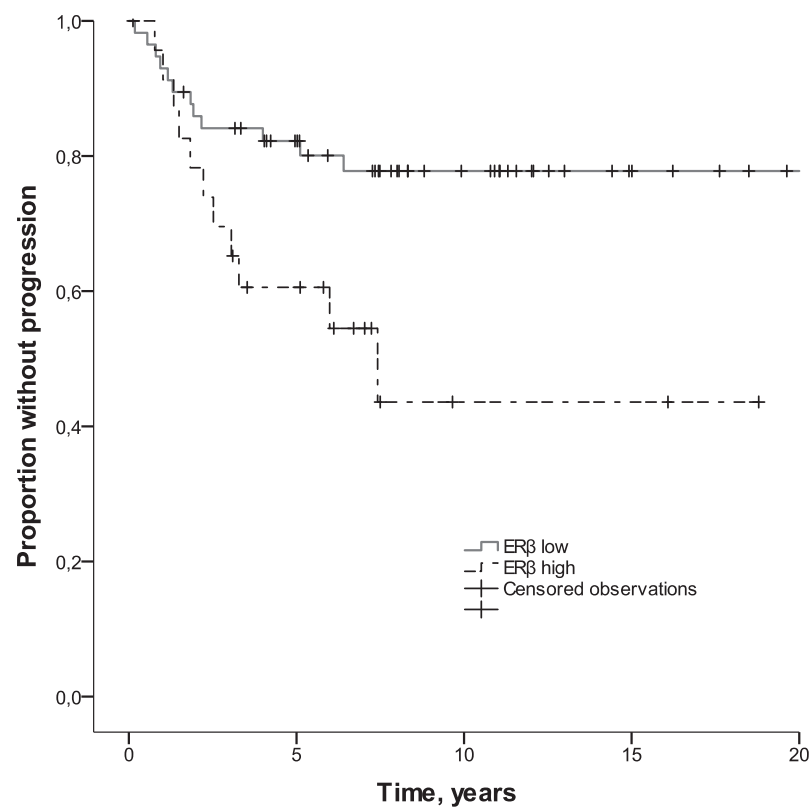

FIGURE 2 Kaplan-Meier analysis of ER $\beta$ expression and time to recurrence using $28.7 \%$ cut-off in 81 patients with resected desmoid tumor. ER $\beta$, Estrogen receptor beta
Despite the documented hormonal dependence of desmoid tumors, expression of ER $\alpha$ has been negative in the vast majority of studies. ${ }^{3,15}$ An earlier report suggested that ER $\alpha$ antibody crosslinkage with ER $\beta$ may have elicited a few positive ER $\alpha$ findings. ${ }^{16}$ Many previous studies have, however, reported that $E R \beta$ is expressed in desmoid tumors. ER $\beta$ overexpression has varied from $7 \%$ to $100 \%$ with cut-offs from any positivity to $10 \%{ }^{3,5,16-18}$ The first ER $\beta$ expression studies with a $10 \%$ cut-off reported only $9 \%(7 / 80)$ and $7 \%(2 / 27)$ positivity. ${ }^{3,18}$ With the lower $1 \%$ cut-off in the present study ER $\beta$ was positive in $82 \%(68 / 83)$ of patients with a median expression value of $10.8 \%$. A previous study with the same $1 \%$ cut-off reported a $90 \%$ positivity rate $(53 / 59) .^{5}$ Other investigators found a $100 \%$ ER $\beta$ expression in 27 and 40 desmoid tumor patients when the cut-off was set at $5 \%$ or detectable staining, respectively. ${ }^{16,17}$ Besides different cut-offs, different antibody clones, immunohistochemistry methods, scoring methods, and patient population selection may explain the somewhat divergent results. The majority of studies, like the present one, show that ER $\beta$ is expressed in a large proportion of desmoid tumors. The proportion of positive cells is relatively low.

Cyclin D1 was expressed in the majority of desmoid tumors in our study but, like ER $\beta$, at a relatively low rate with a medium value of $15.6 \%$. A previous study reported cyclin D1 positivity in $44 \%(30 / 69)$ of patients with a $10 \%$ cut-off. ${ }^{19}$ Two previous studies using a cut-off of $5 \%$ showed cyclin D1 positivity in $71 \%(27 / 38)$ in sporadic and $64 \%(11 / 17)$ in FAP-associated desmoid tumors. ${ }^{6,15}$ Although somewhat higher ( $82 \%$ and $64 \%$ with cut-offs at $5 \%$ and $10 \%$, respectively) than in previous studies, our results and the previous studies indicate 
that cyclin D1 is expressed in a large proportion of desmoid tumors, but in most cases at a relatively low level. Cyclin D1 expression in desmoid tumors may be related to the connection between $\beta$-catenin expression and cyclin D1. ${ }^{6}$ The cyclin D1 gene CCND1 is a transcriptional target of the Wnt/ $\beta$-catenin signaling pathway and the effect may be reinforced by the amplification of the CCND1 gene reported to be frequent in desmoid tumors. ${ }^{6}$

In the present study, cyclin D1 expression was associated with increased proliferation measured by the expression of Ki67 $\left(r_{\mathrm{p}}=0.4\right)$ and cyclin A ( $\left.r_{\mathrm{p}}=0.3\right)$. A previous study by Saito et $\mathrm{al}^{6}$ did not find any significant association between cyclin D1 and Ki67 expression in desmoid tumors, however, a significant association between cyclin D1 expression and the proliferation antigen PCNA was reported. The low number of patients $(n=38)$ might be the reason for the discrepant associations between cyclin D1 and the two proliferation markers but the final cause remains unclear. It is to be pointed out, however, that the correlation between cyclin D1 and proliferation, despite being significant, was not strong in the present study. This indicates that other factors in addition to cyclin D1 are responsible for activation of the cell cycle in this disease.

In breast cancer, there is a close relationship between ER expression and the effect on cyclin D1 expression on cell cycle activation and prognosis. ${ }^{7}$ To test whether this is the case also in desmoid tumors, we tested the association between cyclin D1 and proliferation separately in groups defined by ER $\beta$ expression. We found no signs of modification of ER $\beta$ expression on the association between cyclin D1 and increased proliferation in the present study. This indicates that the interplay between estrogen, estrogen receptor, cyclin D1, and cell cycle activation is different in desmoid tumors and breast cancer.

The function of ER $\beta$ is tissue-specific, and in breast cancer, in contrast to $E R \alpha$ signaling, $E R \beta$ signaling suppresses proliferation; whereas ER $\beta$ has been described to have a role in tissue regeneration after muscle injury, indicating a different role in mesenchymal tissues. $^{4,20}$ To our knowledge, this is the first study in desmoid tumors to show a positive correlation between proliferation markers and ER $\beta$ expression. The association between ER $\beta$ expression found in the present study as well as its tentative predictive effect indicates that ER $\beta$ expression may play a role in the pathophysiology of desmoid tumors. The association may be a part of the signaling pathway linking endocrine factors to the growth of the desmoid tumor.

The advantages and the limitations of the patient material, TMA technique, and immunohistochemistry are discussed in our earlier work. ${ }^{14}$ Briefly, strengths of the study include a histological reevaluation of all diagnoses and long and complete follow-up; a potential weakness is the use of TMA instead of whole sections.

\section{5 | CONCLUSIONS}

In conclusion, in the current study, we showed that both ER $\beta$ and cyclin D1 often are expressed in desmoid tumors, but generally at a low level. Both markers were associated with increased proliferation as assessed by cyclin A and Ki67 expression, and ER $\beta$ expression may also be associated with a higher risk of relapse.

\section{ACKNOWLEDGEMENTS}

The authors are grateful to Päivi Peltokangas for her assistance. The study was supported by Finska Läkaresällskapet and Helsinki University Hospital Research funds (KS), Sigrid Jusélius Foundation, and Medicinska Understödsföreningen Liv och Hälsa (CH).

\section{CONFLICT OF INTERESTS}

The authors declare that there are no conflict of interests.

\section{ORCID}

Kirsi Santti (D) http://orcid.org/0000-0002-5557-6985

\section{REFERENCES}

1. Reitamo JJ, Häyry P, Nykyri E, Saxen E. The desmoid tumor. I. Incidence, sex-, age- and anatomical distribution in the Finnish population. Am J Clin Pathol. 1982;77:665-673.

2. Mosselman S, Polman J, Dijkema R. ER beta: identification and characterization of a novel human estrogen receptor. FEBS Lett. 1996;392:49-53.

3. Leithner A, Gapp M, Radl R, et al. Immunohistochemical analysis of desmoid tumours. J Clin Pathol. 2005;58:1152-1156.

4. Paterni I, Granchi C, Katzenellenbogen JA, Minutolo F. Estrogen receptors alpha (ERalpha) and beta (ERbeta): subtype-selective ligands and clinical potential. Steroids. 2014;90:13-29.

5. Santos GA, Cunha IW, Rocha RM, et al. Evaluation of estrogen receptor alpha, estrogen receptor beta, progesterone receptor, and CKIT expression in desmoids tumors and their role in determining treatment options. Bioscience Trends. 2010;4:25-30.

6. Saito T, Oda Y, Tanaka K, et al. Beta-catenin nuclear expression correlates with cyclin D1 overexpression in sporadic desmoid tumours. J Pathol. 2001;195:222-228.

7. Ahlin C, Lundgren C, Embretsén-Varro E, Jirström K, Blomqvist C, Fjällskog ML. High expression of cyclin D1 is associated to high proliferation rate and increased risk of mortality in women with ERpositive but not in ER-negative breast cancers. Breast Cancer Res Treat. 2017;164:667-678.

8. Goel S, DeCristo MJ, McAllister SS, Zhao JJ. CDK4/6 inhibition in cancer: beyond cell cycle arrest. Trends Cell Biol. 2018;28:911-925.

9. $\mathrm{Hu}$ W, Sung T, Jessen BA, et al. Mechanistic investigation of bone marrow suppression associated with palbociclib and its differentiation from cytotoxic chemotherapies. Clin Cancer Res. 2016;22: 2000-2008.

10. Finn RS, Dering J, Conklin D, et al. PD 0332991, a selective cyclin D kinase 4/6 inhibitor, preferentially inhibits proliferation of luminal estrogen receptor-positive human breast cancer cell lines in vitro. Breast Cancer Res. 2009;11:R77.

11. Turner NC, Slamon DJ, Ro J, et al. Overall survival with palbociclib and fulvestrant in advanced breast cancer. $N$ Engl $J$ Med. 2018;379:1926-1936.

12. Slamon DJ, Neven P, Chia S, et al. Phase III randomized study of ribociclib and fulvestrant in hormone receptor-positive, human 
epidermal growth factor receptor 2-negative advanced breast cancer: MONALEESA-3. J Clin Oncol. 2018;36:2465-2472.

13. Goetz MP, Toi M, Campone M, et al. MONARCH 3: abemaciclib as initial therapy for advanced breast cancer. J Clin Oncol. 2017;35:3638-3646.

14. Santti K, Ihalainen H, Rönty M, et al. High cyclin A expression, but not $\mathrm{Ki67}$, is associated with early recurrence in desmoid tumors. J Surg Oncol. 2018;118:192-198.

15. Colombo C, Foo WC, Whiting D, et al. FAP-related desmoid tumors: a series of 44 patients evaluated in a cancer referral center. Histol Histopathol. 2012;27:641-649.

16. Deyrup AT, Tretiakova M, Montag AG. Estrogen receptor-beta expression in extraabdominal fibromatoses: an analysis of 40 cases. Cancer. 2006;106:208-213.

17. Mignemi NA, Itani DM, Fasig JH, et al. Signal transduction pathway analysis in desmoid-type fibromatosis: transforming growth factorbeta, COX2 and sex steroid receptors. Cancer Sci. 2012;103: 2173-2180.

18. Ishizuka $M$, Hatori $M$, Dohi $O$, et al. Expression profiles of sex steroid receptors in desmoid tumors. Tohoku J Exp Med. 2006;210: 189-198.
19. Jilong Y, Jian W, Xiaoyan Z, Xiaoqiu L, Xiongzeng Z. Analysis of APC/ beta-catenin genes mutations and Wnt signalling pathway in desmoid-type fibromatosis. Pathology. 2007;39:319-325.

20. Velders M, Schleipen B, Fritzemeier KH, Zierau O, Diel P. Selective estrogen receptor-beta activation stimulates skeletal muscle growth and regeneration. FASEB J. 2012;26:1909-1920.

\section{SUPPORTING INFORMATION}

Additional supporting information may be found online in the Supporting Information section at the end of the article.

How to cite this article: Santti K, Ihalainen H, Rönty M, et al. Estrogen receptor beta expression correlates with proliferation in desmoid tumors. J Surg Oncol. 2019;1-7.

https://doi.org/10.1002/jso.25407 